\title{
Penilaian Para Ulama Islam Terhadap Metode Tafsiran Aliran Salafiyyah Kontemporari ke atas Ayat Sifat
}

\author{
Evaluation of Muslim Scholars on the Method of Interpretations of Verses \\ on Divine Attributes by Contemporary Salafi School
}

\author{
NORASIMAH HAJI OMAR* \& MAZLAN IBRAHIM ${ }^{1}$
}

\begin{abstract}
The emergence of contemporary Salafi school in the mainstream Muslims is intended to make the Ahl al-Salaf as the primary models of faith and to return the related problems of faith according to the path taken by the companions and tabi'in, which had been quoted only from the al-Quran and al-Sunnah. These stances left great influences on their method of interpretations upon the Quranic verses including the Ayat al-Sifat (verses on Divine Attributes) and condemning others out of the Ahl al-Sunnah wa al-Jama'ah. Therefore this research is intended to identify responses of Muslim figures and scholars against the Contemporary Salafi School's stances and their method of interpretations on Ayat al-Sifat. In addition, this research is also intended to explain the views of the majority of scholars on the conceptual and methods of interpretation of Ayat al-Sifat adopted by the Ahl alSunnah wa al-Jama'ah. The paper is produced with the synthesization of content analysis that focuses on published works by selected Contemporary Salafi school figures and other muslim scholars and also relevant contemporary researchers in relation to these issues of Ayat al-Sifat and its methods of interpretations. The results of this research found that most scholars do not accept the method of literal interpretations on Ayat al-Sifat proclaimed by Contemporary Salafi School due to the existence of two catogeries of the Quranic verses, which are known as Wadih Jalli and Khafi Mutashabih or Mutashabih al-Sifat. In certain cases, the method of 'ta'wil' is highly needed to clarify the meaning of Ayat al-Sifat so easily understood by human intellect and at the same time to purify Allah the almighty from signs of weaknesses and resemblance. The extreme acts from Contemporary Salafi School in defending their methods of interpretations make them an 'exclusive' school which separated themselves from other muslims, and limit the diversity of the methods of interpretations enabled by the majority of mufassirin.
\end{abstract}

Keywords: Divine Attributes, Quranic exegesis, salafal-salih, salafism, Sunni

Ayat Sifat dan tafsirannya dianggap salah satu isu yang mencetuskan perbahasan di kalangan para ulama dan ahli teologi Islam. Hal ini menarik para pengkaji kontemporari untuk menjadikannya sebagai tema kajian, antaranya al-Qaradawi (2005: 26) dalam tulisannya berjudul "Fusul fi al-'Aqidah bayn al-Salaf wa al-Khalaf", yang menyifatkan isu tersebut sebagai salah satu permasalahan yang berterusan di kalangan umat ini. 'Izzah Mohammed Hasan (1993:

\footnotetext{
${ }^{1}$ Norasimah Haji Omar* (corresponding author), Ph.D. student at Centre for Akidah and Global Peace, Faculty of Islamic Studies, Universiti Kebangsaan Malaysia, 43600 BANGI, Selangor, Malaysia, email: norasimah.omar@gmail.com; Mazlan Ibrahim, Ph.D., assoc. professor at Centre for Akidah and Global Peace, Faculty of Islamic Studies, Universiti Kebangsaan Malaysia, 43600 BANGI, Selangor, Malaysia, email: mazib@ukm.edu.my.
} 
3) pula menyifatkan tafsiran ayat-ayat tersebut sebagai satu perbahasan penting yang menjadi tumpuan para ulama Islam khususnya. Sementara Muhammad Rashidi \& Syed Hadzrullathfi (2012: 77) pula dalam hasil kajian mereka berpendapat bahawa isu ini telah berlarutan dalam pemikiran umat Islam sejak kurun awal Hijrah lagi hingga kini.

Penitikberatan para ulama dan ahli teologi Islam terhadap permasalah sifat dan tafsirannya adalah merujuk kepada wujudnya hubungan secara langsung di antara sifat-sifat tersebut dengan konsep tanzih yang didukung oleh Ahl al-Sunnah wa al-Jama'ah, sebagaimana yang dinyatakan oleh 'Abd al-Ghani (1406H: 112) dalam "Usul al-'Aqidah al-Islamiyyah", dan beliau menegaskan bahawa memahami konsep sifat bagi Allah SWT adalah sangat penting. Manakala al-Qaradawi (2005: 21) pula menekankan bahawa hal tersebut sangat berkaitan dengan akidah ketuhanan yang menjadi asas dalam akidah Islam. Oleh itu, al-Khatib (2010: 554) dalam "Mafatih al-Tafsir" menjelaskan bahawa sifat-sifat Allah adalah suatu yang terawal perlu diimani dan menjadi kewajipan setiap muslim untuk menyifatkan Allah dengan sifat-sifat kesempurnaan serta mensucikan-Nya daripada sebarang kekurangan.

Bertitik-tolak daripada kepentingan tersebut, ramai daripada kalangan mufassirin dan ahli teologi Islam tampil dengan metode-metode tafsiran dan pandangan mereka untuk menjelaskan makna ayat-ayat Sifat dalam al-Quran agar ia dapat difahami dan diterima oleh akal dan batas pemikiran manusia. Perkara ini pada dasarnya selaras dengan tujuan asal penurunan al-Quran, iaitu untuk menjadikan manusia lebih mengenali Allah, mentauhidkan-Nya, menumpukan ibadah hanya kepada-Nya dan mensucikan-Nya daripada sebarang kekurangan (al-Qaradawi 2005: 13).

Walau bagaimanapun, kemunculan beberapa metode tafsiran yang dikemukakan bagi menjelaskan ayat-ayat tersebut mengakibatkan pengelompokan para mufassir kepada beberapa aliran. Al-Zarkashi (1988: 78) dalam "al-Burhan fi 'Ulum al-Quran" dan al-Zarqani (1988: 306) dalam "Manahil al-'Irfan fi 'Ulum al-Quran" membahagikan golongan tersebut kepada tiga aliran atau madhhab, iaitu i. golongan yang tidak menerima ta'wil, bahkan menerima sifat-sifat itu pada zahirnya; ii. golongan yang menerima ta'wil dan pada masa yang sama mensucikan sifat-sifat tersebut daripada sebarang penyerupaan dengan makhluk serta tidak menafikan sifat-sifat tersebut ( $\left.{ }^{\prime}{ }^{\prime} t \bar{I}\right)$; dan iii. golongan yang mentakwilkan sifat-sifat tersebut dengan makna yang bersesuaian dengannya. Akan tetapi, kebanyakan ulama hanya membahagikan mereka kepada dua kelompok utama, iaitu Salaf dan Khalaf (al-Bayjuri 2004: 104; al-Zuhayli 1988: 343; alQaradawi 2005: 21). Golongan Salaf adalah mereka yang mengimani sifat-sifat Allah sebagaimana yang disifatkan oleh Allah bagi diri-Nya, tanpa penyerupaan, tamsilan dan penolakan. Golongan Khalaf pula adalah mereka yang mentakwil sifat-sifat tersebut dengan makna yang bersesuaian dengannya (al-Zuhayli 1988: 343; al-Qaradawi 2005: 29). Al-Zuhayli (1988: 343) menetapkan bahawa pendekatan Salaf merupakan pegangan Ahl al-Sunnah wa al-Jama'ah keseluruhannya.

\section{Konsep Ayat Sifat dan Metode Tafsirannya Menurut Para Ulama dan Mufassirin}

Secara etimologi, lafaz "Ayat Sifat" terbentuk daripada dua kata, iaitu 'ayat' dan 'sifat'. Sebagaimana yang dijelaskan pengertiannya oleh kebanyakan ulama, antaranya al-Razi (N.d.: 39), al-Juhari (2009: 68) dan al-Khatib (2010: 25) bahawa kata 'ayat' diertikan dengan "alamat atau kumpulan" dan jika dikaitkan kata tersebut dengan kitab Allah, maka ia bermaksud "kumpulan huruf-huruf".

Kata 'sifat' pula diertikan oleh al-Jurjani (1983: 133) dengan "nama yang menunjukkan kepada sebahagian perihal zat seperti panjang, pendek, berakal, dungu dan sebagainya". 'Abd alMun'im (N.d.: 373) dalam Mu'jam al-Mustalahat wa al-Alfazh al-Fiqhiyyah mendefinisikannya dengan "suatu ibarat yang melazimi bagi zat yang disifati dengannya atau ibarat yang berdiri dengan zat yang disifati dengannya". Sementara 'Abd al-Ghani (1406H: 112) mentakrifkannya dengan "sesuatu yang wujud pada mawsuf (sesuatu yang disifati padanya)". Justeru itu, dapat 
dirumuskan bahawa kata 'sifat' membawa maksud "sesuatu yang wujud pada mawsuf (zat) dan melaziminya serta menjelaskan perihal zat tersebut".

Secara terminologi pula, al-Qaradawi (2005: 20) memberikan sebuah definisi yang dianggap menyeluruh dan lengkap bagi "Ayat Sifat", iaitu "nas-nas al-Quran yang menunjukkan perbuatan atau sifat yang disandarkan kepada Allah SWT yang mempunyai ciri persamaan dengan perbuatan atau sifat makhluk". Definisi ini adalah selaras dengan kebanyakan pengertian "Ayat Sifat" yang dikemukakan oleh pengkaji-pengkaji kontemporari lain, yang antaranya lebih ringkas daripada definisi yang dikemukakan oleh al-Qaradawi itu, seperti mendefinisikannya dengan "ayat-ayat yang menyebutkan tentang sifat dan keadaan Allah" (Sarinah Yahya 2015: 214).

Berkaitan dengan definisi Ayat Sifat yang dinyatakan di atas, perlu dijelaskan di sini bahawa para ulama telah mengklasifikasikan perbuatan-perbuatan dan sifat-sifat Allah itu kepada Thubutiyyah dan Khabariyyah. Shahrastani (2006: 44) dan al-Qaradawi (2005: 21) menetapkan bahawa antara perbuatan-perbuatan dan sifat-sifat yang termasuk dalam sifat Thubutiyyah ialah sifat ilmu, kehendak, kuasa, hidup, mendengar, melihat, berkata-kata, agung, memuliakan, pemurah, memberi nikmat, berkebesaran dan keagungan. Shahrastani (2006: 44) kemudian menyatakan bahawa sebahagian ulama juga menamakan sifat ini dengan sifat Azaliyyah, sepertimana yang ditetapkan oleh majoriti Salaf bagi Allah. Dalam hal ini, mereka tidak membezakan di antara sifat-sifat zat dan sifat-sifat perbuatan, malahan membicarakan dalam satu hala, sebagaimana mereka juga menetapkan kepada Allah sifat Khabariyyah tanpa mentakwilkannya.

Adapun sifat Khabariyyah didefinisikan oleh al-Qaradawi (2005: 21) sebagai "sifat yang disebutkan dalam nas-nas shar'iyyah yang menetapkan bagi Allah sifat-sifat yang boleh memberikan kesamaran penyerupaan Allah dengan makhluk", iaitu menetapkan bagi Allah anggota badan, seperti tangan, kaki, mata dan wajah. Ia juga terdiri daripada perihal pergerakan, seperti datang pada hari kiamat, turun ke langit dunia, Istiwa' di atas 'Arash, membentang tangan dan lain-lain lagi. Juga perihal keberadaan yang menggambarkan sesuatu arah, seperti pada ketinggian atau di atas. Di samping itu, termasuk dalam sifat Khabariyyah ialah nas-nas yang menyandarkan beberapa perbuatan kepada Khaliq, yang lafaz zahirnya menyerupai perbuatan makhluk seperti gembira, belas kasihan, kasih, benci dan lain-lain lagi.

Walau bagaimanapun, sebahagian ulama yang datang selepas Salaf telah menetapkan sifatsifat Allah itu kepada dua bahagian utama, iaitu sifat al-Dhat dan sifat al-Af'al, yang merujuk kepada pembahagiannya ke atas nama-nama Allah. Al-Ashqar (2004: 83) mencatatkan bahawa termasuk dalam kedua-dua sifat itu ialah sifat Khabariyyah mengikut makna yang terkandung dalam sifat-sifat itu, seperti sifat yang menetapkan tangan, wajah, mata dan lain-lain lagi bagi Allah dalam sifat al-Dhat; dan sifat Istiwa', Nuzul, Maji' dan lain-lain lagi dalam sifat al-Af'al.

Justeru para ulama memasukkan dalam definisi "Ayat Sifat" itu nas-nas al-Quran yang menyebutkan Asma' al-Husna, sebagaimana hujah yang dibentangkan oleh al-Ashqar (224: 88) yang menetapkan bahawa Asma' al-Husna adalah termasuk dalam sifat-sifat Allah, kerana setiap nama-nama Allah itu menjelaskan sesuatu sifat dari segi petunjuknya, seperti 'al-Qadir' yang menunjukkan kepada sifat 'Qudrah', 'al-Sami' menunjukkan kepada sifat mendengar dan lain-lain lagi. Terdapat juga lebih satu nama yang menjelaskan sesuatu sifat, seperti 'al-Rahman' dan 'alRahim' yang menunjukkan sifat 'Rahmat'. Penetapan ini disokong oleh pendapat al-Khatib (2010: 554) yang menyatakan bahawa semua sifat itu secara tawqifi disebutkan dalam al-Quran dan alSunnah.

Merujuk kepada pernyataan-pernyataan di atas, secara keseluruhannya diperhatikan bahawa para ulama mengemukakan definisi yang seragam bagi "Ayat Sifat". Sementara pembahagian sifat-sifat Allah yang disebutkan dalam al-Quran dikategorikan kepada dua bahagian utama, iaitu sifat al-Dhat dan sifat $a l-A f^{\prime} a l$. Dan setiap bahagian sifat tersebut meliputi sifat-sifat Thubutiyyah dan Khabariyyah. Memandangkan setiap nama-nama Allah menunjukkan 
kepada sesuatu sifat, maka nas-nas al-Quran yang menyebutkan Asma' al-Husna juga dikategorikan dalam pengertian "Ayat Sifat".

Akan tetapi, para ahli teologi Islam dan mufassirin tidak sependapat dalam menetapkan ayat-ayat Sifat sebagai ayat Muhkamat atau Mutashabihat. Al-Khatib (2010: 554) mencatatkan bahawa sebahagian ulama membahagikan ayat-ayat tersebut kepada dua bahagian, iaitu Wadih Jalli, yang bermaksud sifat yang jelas lafaz dan maknanya, dan Khafi Mutashabih atau Mutashabih al-Sifat, yang bermaksud sifat yang samar dan tidak mampu digambarkan oleh akal manusia.

Sementara kebanyakan ulama pula mengkategorikannya dalam ayat Mutashabihat. AlZarqani (1988: 306) misalannya, mengkhususkan Ayat Sifat itu kepada ayat-ayat yang samar berkaitan dengan Allah atau Mutashabih al-Sifat dengan hujah bahawa ia adalah salah satu bentuk Mutashabihat yang tidak mampu dicapai dan digambarkan oleh manusia. Pendapat ini selaras dengan pernyataan al-Suyuti (1991: 9) dalam al-Itqan fi 'Ulum al-Quran yang menukilkan pendapat para ulama, antaranya al-Raghib al-Asfahani, menekankan bahawa ayat-ayat Sifat merupakan salah satu jenis Mutashabihat dari segi makna. Sementara al-Qaradawi (2005: 34) menukilkan pendapat Hasan al-Banna, bersepakat dengan jumhur ulama yang mengkategorikan ayat-ayat Sifat sebagai ayat Mutashabihat berdasarkan pengistilahannya sebagai ayat yang berlaku kekaburan dalam makna yang dikehendakinya.

Walau bagaimanapun, pengkategorian dan hujah-hujah yang dikemukakan oleh para ulama di atas ditolak oleh sebahagian ulama yang lain, antaranya Ibn Taymiyyah (1381H: 310 ), yang tidak bersetuju mengkategorikan ayat-ayat Sifat dalam ayat Mutashabihat kerana pada pendapat beliau bahawa makna ayat-ayat tersebut adalah jelas dan kebanyakannya boleh difahami. Justeru beliau mencela takwilan yang dilakukan ke atas ayat-ayat tersebut.

Berasaskan perbezaan para ulama dalam pengkategorian Ayat Sifat, secara langsung telah melahirkan dua metode masyhur dalam mentafsirkan ayat-ayat Sifat (al-Buti 1990: 133; alAnjari \& al-Masri 2013: 144), iaitu: i. Tafwid atau Ta'wil Ijmali, bermaksud tidak melakukan ta'wil secara tafsili, menerima pakai makna umum qat'ie yang disepakati oleh semua ulama dan menyerahkan makna yang sebenar kepada Allah; dan ii. Ta'wil atau Ta'wil Tafsili, bermaksud memberikan makna selain zahir sifat (al-Bayjuri 2004: 104). Sebagai tambahan, al-Zarqani (1988: 310) mencatatkan bahawa selain dua metode tersebut, terdapat sebilangan ulama berpendapat bahawa jika nas-nas Mutashabihat itu berada dekat dengan lingkungan bahasa Arab dan sesuai untuk melakukan ta'wil, maka pentakwilannya adalah diharuskan, akan tetapi jika sebaliknya, maka mereka mengambil sikap berdiam diri (tawaqquf). Justeru al-Zuhayli (1988: 344) dalam "Usul al-Fiqh al-Islami" mensyaratkan bahawa keharusan mentakwil nas-nas Mutashabihat memerlukan kepada beberapa syarat penting agar kesucian nas al-Quran atau hadith berkaitan sifat Allah tetap terpelihara.

Adapun penolakan golongan yang tidak menerima ta'wil merupakan kesan pendirian mereka dalam memahami firman Allah dalam Surah Ali 'Imran (3: 7):

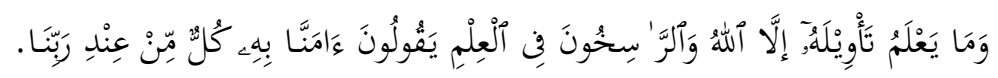

Maksudnya: Padahal tidak ada yang mengetahui takwilnya (tafsir maksudnya yang sebenar) melainkan Allah. Dan orang-orang yang tetap teguh serta mendalam pengetahuannya dalam ilmu-ilmu ugama, berkata: "Kami beriman kepadanya, semuanya itu datangnya dari sisi Tuhan kami".

Para ulama tersebut mentarjihkan huruf ' $w a w$ ' di hadapan kalimah 'al-Rasikhun' dalam ayat di atas sebagai 'waw al-Isti'naf' (al-Zarkashi 1988: 72; al-Bayjuri 2004: 104; al-Qaradawi 2005: 35). Dalam hal ini, al-Suyuti (1991: 5) menegaskan bahawa pendapat tersebut merupakan pendapat kebanyakan ulama. Al-Qaradawi (2005: 36) juga memperakui pendapat tersebut dengan menyatakan bahawa hanya sekelompok kecil ulama sahaja yang menetapkannya sebagai 'waw li al-'Ataf', antaranya Mujahid dan Ibn 'Abbas. 


\section{Kemunculan Aliran Salafiyyah Kontemporari dalam Arus Perdana Umat Islam}

Muhammad Abu Zahrah (n.d. 177) mencatatkan kronologi kemunculan golongan Salafiyyah adalah berasal daripada kalangan Hanabilah, iaitu para pengikut Imam Ahmad bin Hanbal, yang kemudiannya diformulasikan secara lengkap oleh Ibn Taymiyyah pada abad ke-7H. Golongan ini berkembang di Jazirah Arab oleh Muhammad bin 'Abd al-Wahhab pada abad ke-12H. Yahya Hashim Hasan (2000: 439) juga memberikan pendapat yang sama dengan menyatakan bahawa Salafiyyah ialah "suatu kelompok Hanabilah yang bermula dari Imam Ahmad bin Hanbal, berkembang dengan Ibn Taymiyyah dan berkesudahan dengan Muhammad bin 'Abd al-Wahhab".

Khalif Muammar (2012: 167) dalam tulisannya menjelaskan bahawa Salafiyyah sebenarnya membawa maksud suatu aliran yang ingin menjadikan Ahl al-Salaf sebagai ikutan dan panduan. Muhammad Abu Zahrah (N.d.: 178) juga menyatakan bahawa tujuan asal golongan ini adalah ingin mengembalikan agar masalah-masalah akidah hendaklah mengikut jalan yang ditempuh oleh para sahabat dan tabi'in yang hanya berdalilkan al-Quran dan al-Sunnah. Malahan, mereka juga menamakan diri mereka sebagai 'Muwahhidun' (pendukung tauhid Allah), kerana cita-cita mereka untuk mengembalikan ketulinan ajaran Tauhid dalam Islam dan kehidupan murni menurut Sunnah Nabi SAW (Aboebakar Atjeh N.d.: 103).

Penambahan kata 'Kontemporari' ke atas 'Salafiyyah' dibataskan awalan waktunya oleh Aboebakar Atjeh (N.d.: 103) dengan kemunculan Muhammad bin 'Abd al-Wahhab di Najd sebagai tokoh yang signifikan dalam aliran ini. Al-Saqqaf (2007: 19) pula memberikan pengenalan kepada Salafiyyah Kontemporari sebagai para pengikut Ibn Taymiyyah dan imam-imam golongan Hanabilah al-Mujassimah yang berada di luar Jazirah 'Arabiyyah. Menurutnya lagi, Salafiyyah dan Wahabiyyah merupakan nama ke atas satu aliran pemikiran yang sama. Andi Aderus (2012: 13) pula menjelaskan bahawa kelompok yang tidak menyenangi pemaksaan pemikiran yang dikembangkan oleh Muhammad bin 'Abd al-Wahhab lebih cenderung menamakan golongan tersebut sebagai Wahabiyyah dan bukan Salafiyyah.

Penamaan golongan pengikut aliran pemikiran Muhammad bin 'Abd al-Wahhab ke atas diri mereka dengan Salafiyyah disifatkan oleh Andi Aderus (2012: 15) sebagai suatu usaha untuk memahamkan dan menarik perhatian umat Islam bahawa perjuangan atau reformasi akidah yang mereka lakukan bertujuan memerangi khurafat, bid'ah dan takhayyul adalah bersumberkan para Salaf yang hidup pada tiga abad pertama umat Islam, di samping ingin mempertahankan pegangan Salafi yang mereka cetuskan sehingga terbentuknya komuniti tersendiri dengan ciri khusus yang berbeza daripada muslim lainnya. Akan tetapi, pandangan ini ditolak oleh al-Hilaly (2001: 57) dengan pendapatnya yang menyatakan bahawa penggunaan istilah 'Salafiyyah' ke atas penamaan golongan tersebut menunjukkan kepada firqah al-Najiyah, al-Ta'ifah al-Mansurah, alGhuraba' dan Ahl al-Hadith yang diisyaratkan dalam hadith-hadith Nabi SAW, dan ia merujuk kepada Ahl al-Sunnah wa al-Jama'ah.

Al-Hilaly (2001: 104) menegaskan bahawa istilah Ahl al-Sunnah wa al-Jama'ah telah menjadi istilah yang umum sehingga kelompok-kelompok yang menyeleweng dalam masalah akidah, khususnya berkaitan nama-nama dan sifat-sifat Allah, telah masuk ke dalamnya. Justeru itu, menjadi suatu keperluan untuk menggunakan istilah 'Salafiyyah' yang meliputi maksud "firqah Najiyah, al-Ta'ifah al-Mansurah, al-Ghuraba' dan Ahl al-Hadith". Justeru itu, al-Buti (1990: 13) berpendapat bahawa penggunaan konsep 'Salafiyyah' pada kebelakangan ini telah tersasar daripada hakikat sebenarnya, kerana ia telah menjadi satu aliran pemikiran atau mazhab khusus bagi golongan tertentu dan menolak ulama lain yang dianggap telah menyimpang daripada kebenaran. Khalif Muammar (2012: 165) pula menyifatkan golongan ini sebagai Pseudo-Salafi atau Ghulat al-Salafiyyah kerana ciri-ciri ektrimisme atau al-ghuluw fi al-din yang mereka miliki dan merupakan satu fenomena baru yang muncul kebelakangan ini serta sering diperdebatkan. 


\section{Metode Tafsiran Ayat Sifat Menurut Aliran Salafiyyah Kontemporari}

Ketekalan aliran Salafiyyah Kontemporari dalam menegakkan pendirian asas mereka, iaitu untuk mengembalikan masalah-masalah berkaitan akidah kepada jalan yang ditempuh oleh para sahabat dan tabi'in yang hanya berdalilkan al-Quran dan al-Sunnah mempengaruhi metode tafsiran mereka ke atas nas-nas al-Quran dan hadith.

Al-Hilaly (2001: 42) mencatatkan pendirian tegas mereka itu dalam mewarisi pegangan Ahl al-Salaf dan melabelkan diri mereka sebagai golongan Ahl al-Sunnah wa al-Jama'ah dalam sumber pengambilan dan pemahaman terhadap al-Quran dan al-Sunnah. Dalam fatwa yang dikemukakan oleh tokoh-tokoh aliran ini menegaskan bahawa Ahl al-Sunnah wa al-Jama'ah ialah golongan yang berpegang dengan kitab Allah dan Sunnah Nabi dalam akidah dan Usuluddin, tidak menyanggah dalil-dalil daripada dua sumber tersebut dengan akal dan hawa nafsu mereka serta sentiasa berpegang dengan pegangan para sahabat RA. Maka, sesiapa yang keluar dari jalan para sahabat dalam masalah Usuluddin, sama ada banyak atau sedikit, mereka itu telah melakukan bid'ah dan melakukan kesalahan atas apa yang mereka iktikadkan (al-Lajnah al-Da'imah li alBuhuth al-'Ilmiyyah wa al-Ifta' 1412H: 177).

Mustafa Hilmi (2005: 161) menjelaskan bahawa aliran Salafiyyah Kontemporari menggunakan metodologi tekstual dalam tafsiran mereka dengan berpegang kepada teks-teks wahyu dan bersikap berhati-hati terhadap penggunaan akal yang mendalam dalam masalahmasalah yang berkaitan dengan akidah. Al-Qaradawi (2005: 47) juga menyatakan bahawa aliran ini merupakan sebuah aliran yang hanya mentafsirkan ayat-ayat al-Quran dan hadith secara literal tanpa menerima sebarang tafsiran lain. Malahan, mereka menetapkan bahawa takwilan yang dilakukan oleh golongan lain merupakan suatu penyimpangan (al-Utsaimin 2014: 328).

Pendirian aliran Salafiyyah Kontemporari terhadap penetapan ayat-ayat Sifat secara literal adalah berasaskan beberapa faktor, sebagaimana yang disebutkan oleh al-'Uthaymin (N.d.: 4) dalam karyanya "Fath Rabb al-Bariyyah", bahawa menetapkan ayat-ayat Sifat adalah termasuk dalam beriman kepada Allah, nama-nama-Nya, sifat-sifat-Nya dan perbuatan-Nya, yang menjadi asas dalam beragama dan intipati dakwah para utusan Allah SWT. Maka, menjadi suatu kewajipan dan keutamaan bagi hati manusia untuk meyakini sifat-sifat Allah itu dan akal memahaminya. Sementara al-Lajnah al-Da'imah li al-Buhuth al-'Ilmiyyah wa al-Ifta' (1412H: 124) menyebutkan dalam fatwa mereka bahawa Ahl al-Sunnah wa al-Jama'ah mempunyai pegangan bahawa Allah bersifat dengan setiap sifat kesempurnaan yang disifatkan-Nya ke atas diri-Nya dalam al-Quran dan yang disifatkan oleh Rasul tanpa tahrif, ta'til, takyif dan tamthil.

Al-'Uthaymin (2005: 18) ketika menjelaskan makna "Tawhid al-Asma' wa al-Sifat" dalam kitab "Fatawa al-'Aqidah" berpendapat bahawa wajib beriman dengan nama yang Allah menamakan diri-Nya dan sifat yang Allah menyifatkan diri-Nya secara hakikat tanpa majaz, bentuk dan perumpamaan dengan menetapkan apa yang Allah tetapkannya ke atas diri-Nya tanpa sebarang perubahan atau penafian, tanpa sebarang bentuk dan tanpa sebarang perumpamaan. Justeru itu, aliran Salafiyyah Kontemporari tidak menerima metode ' $t a$ 'wil' disebabkan terdapatnya kesamaan di antara konsep 'ta' wil' dan 'ta'til' pada pandangan mereka, lalu mereka menghukumkannya sebagai bid'ah, seperti takwilan sifat 'استولى ' atau

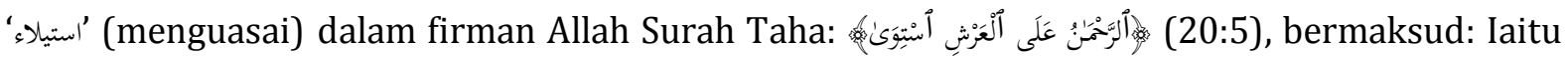
(Allah) al-Rahman, yang bersemayam di atas 'Arash (Al-Lajnah al-Da'imah li al-Buhuth al'Ilmiyyah wa al-Ifta' 1412H: 49).

Aliran Salafiyyah Kontemporari juga berpendirian bahawa ta'wil merupakan salah satu bahagian daripada 'al-Tahrif' atau 'al-Taghyir', kerana berlakunya perubahan pada makna sifat tersebut, atau dengan kata lain bahawa ta'wil itu memalingkan atau mengubah makna daripada zahir lafaz dengan tidak berdasarkan dalil atau keterangan, seperti mengubah makna 'اليَّيَ' (dua belah tangan) yang dinisbatkan kepada Allah kepada 'kekuatan', 'nikmat' atau lain-lain lagi (al'Uthaymin n.d. 8). Justeru mereka menilai takwilan-takwilan yang sedemikian merupakan kesesatan dan sekaligus suatu kejahatan terhadap nas al-Quran, kerana ia hanya berasaskan akal 
yang memustahilkan untuk menyifatkan Allah dengan tangan yang hakiki (al-'Uthaymin 2003: 263).

\section{Respon Para Ulama Islam Terhadap Pendirian Aliran Salafiyyah Kontemporari}

Tanggapan aliran Salafiyyah Kontemporari terhadap pendirian mereka yang mewarisi pendekatan Ahl al-Salaf tidak dapat diterima bulat oleh kebanyakan para ulama Islam dan pengkaji-pengkaji Kontemporari. Hal ini diperhatikan dengan penegasan yang dinyatakan oleh Shahrastani (2006: 42) bahawa terdapat sebahagian Salaf bersikap ekstrem dalam mengithbatkan sifat-sifat sehingga ke tahap menyamakannya dengan segala yang baharu dan sebahagian mereka pula membataskan kepada sifat-sifat yang dibuktikan oleh perbuatanperbuatan dan yang diceritakan oleh khabar.

Oleh itu, Shahrastani (2006: 42) menetapkan bahawa Ahl al-Salaf terbahagi kepada dua kumpulan, iaitu golongan yang mentakwilkan khabar tersebut dalam bentuk memungkinkan bahawa takwilan mereka adalah yang dimaksudkan lafaz ayat-ayat itu dan golongan yang tawaqquf dalam melakukan ta'wil dengan hujah bahawa mereka tidak ditaklifkan untuk mengetahui tafsiran dan takwilan ayat-ayat tersebut dan cukup mengithbatkan sifat-sifat tersebut dengan yakin. Akan tetapi, al-Qaradawi (2005: 65) kemudiannya mengemukakan beberapa dalil tentang pegangan dan pendekatan Ahl al-Salaf terhadap ayat-ayat Sifat, yang menunjukkan bahawa kebanyakan mereka berpegang kepada kaedah 'Tafwid', akan tetapi terdapat di kalangan mereka yang mentakwil dan sebahagiannya pula melakukan 'Ithbat'.

Berasaskan pembahagian pendekatan tersebut, Khalif Muammar (2012: 172) memperakui perbezaan di antara metodologi tafsiran ayat-ayat Sifat yang dipegang oleh aliran Salafiyyah Kontemporari dan Ahli Salaf, kerana Ahli Salaf dikatakan mengambil pendekatan alTafwid, sementara aliran Salafiyyah Kontemporari pula mengambil pendekatan al-Ithbat. Menurutnya, perbezaan di antara kedua-keduanya terlalu halus dan tidak mudah dilihat dengan mata kasar.

Berhubung keharusan takwilan para Ahli Salaf ke atas ayat-ayat Sifat, Mudasir Rosder \& Hamzah Harun (2012: 17) menjelaskan bahawa walaupun Ahl al-Salaf mengutamakan nas daripada akal, bukan bererti mereka menolak akal, malahan mereka menjadikannya sebagai sesuatu yang sekunder. Metode ini memberikan perbezaan di antara Ahli Salaf dan Mu'tazilah, yang mengutamakan akal daripada nas, dan golongan Hanabilah, yang memberi apresiasi berlebihan kepada nas dan melepaskan akal daripada fungsi utamanya.

Pendekatan yang dinyatakan di atas boleh diperhatikan dalam beberapa kitab tafsir para ulama Ahl al-Salaf, misalnya al-Tabari dalam Jami' al-Bayan fi Ta'wil al-Quran, yang dijelaskan oleh al-Sharif $(1984: 77,105)$ bahawa selain berpegang kepada al-Ma'thur dengan menggunakan Isnad atau rangkaian perawi yang kukuh dan berkesinambungan sehingga sampai kepada Rasul Sallallahu 'Alaihi Wa Sallam, sahabat dan tabi'in, al-Tabari juga menggunakan al-Ma'qul, iaitu menjelaskan lafaz-lafaz al-Quran dengan makna lughawi berdalilkan hadith Rasul Sallallahu 'Alaihi Wa Sallam, syair-syair Arab atau perkataan yang lazim digunakan oleh bangsa Arab bagi mengukuhkan lagi tafsiran tersebut dari segi bahasa, di samping memelihara i'rab dengan membawakan pandangan ahli-ahli Nahu dan ulama-ulama Arab serta pakar-pakar bahasanya dengan tujuan menjelaskan makna al-Quran, dan kemudiannya beliau menilai pandanganpandangan itu dan memilih pandangan yang bersesuaian berasaskan kecenderungan bahasa dan nahu.

Malahan, pendekatan tersebut jelas dibuktikan dengan takwilan yang dilakukan oleh al-

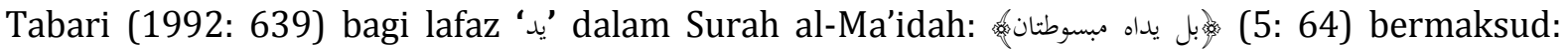
bahkan kedua tangan Allah sentiasa terbuka (nikmat dan kurnia-Nya luas melimpah-limpah)) dengan al-'Ata' (pemberian), dengan hujahnya bahawa setiap pemberian dan belanja yang dikeluarkan oleh seseorang lazimnya menggunakan tangan. 
Mengukuhkan lagi penggunaan Ahl al-Salaf dengan pendekatan yang sama, hasil kajian Muhammad Rashidi \& Syed Hadzrullathfi (2012: 82) juga membuktikan bahawa terdapat golongan daripada Ahl al-Salaf yang menggunakan ta'wil atau ta'wil tafsili sebagaimana Khalaf dalam memahami ayat-ayat Sifat. Antaranya ialah takwilan Ibn Abbas (w. 68H) terhadap perkataan 'kursi' dengan 'ilmu Allah'. Perkataan 'ja'a ditakwilkan oleh Ibn 'Abbas dan Hasan alBasri (w. 110) dengan 'perintah dan kepastian Allah', manakala Imam Ahmad bin Hanbal (w. 241) mentakwilkannya dengan 'datangnya pahala dari Tuhan'. Adapun perkataan 'Istiwa" ditakwilkan oleh Imam Ibn Mubarak (w. 237H) dan al-Tabari (w. 310H) dengan 'memiliki dan menguasai, bukan bergerak dan berpindah', sementara Ibn Hazm (w. 456) mentakwilkannya dengan 'perbuatan menyempurnakan penciptaan yang dilakukan oleh Allah'.

Justeru takwilan yang berasaskan metodologi yang sedemikian, ditetapkan oleh alQaradawi (2005: 84) sebagai takwilan yang diterima dan bukan dibuat-buat, malahan ia selaras dengan metode bahasa Arab yang dipertuturkan oleh bangsa Arab yang dinamakan oleh pakarpakar Balaghah kemudiannya dengan nama Isti'arah (kata-kata pinjaman), Majaz (simbolik) dan Kinayah (kiasan).

Sementara keperluan 'ta'wil' di zaman mutakhir ini diperjelaskan oleh al-Qaradawi (2005: 127) dengan pendapatnya yang bermaksud berikut:

Ta'wil diperlukan pada zaman ini ketika kita menterjemahkan makna-makna alQuran kepada bahasa-bahasa asing, tidak dapat diterima oleh akal orang asing jika kita mengatakan kepada mereka: "dalam perkara ini kami berdiam diri, kami tidak perlu menjelaskan maksudnya, dan kami menyerahkannya kepada Allah", sesungguhnya mereka amat memerlukan penjelasan dan bukan berdiam diri.

Berasaskan penjelasannya di atas, al-Qaradawi (2005: 58) menyatakan bahawa pendapat aliran Salafiyyah Kontemporari berkaitan sifat berdiam diri para Ahl al-Salaf terhadap metode 'ta'wil' itu merupakan suatu perkara yang tidak dapat diputuskan, kerana ketiadaan maklumat terperinci yang menjelaskan hakikat sebenar pendirian mereka dalam menghadapi ayat-ayat dan hadith-hadith Sifat. Menurutnya lagi, secara kaedah fiqhiyyah, tidak boleh dinisbahkan sebarang pendapat kepada orang yang diam (tidak bercakap).

Diperhatikan bahawa adalah tidak keterlaluan - jauh sebelum pendapat yang dikemukakan oleh al-Qaradawi itu, jika Shahrastani (2006: 43) telah merumuskan bahawa aliran Salafiyyah merupakan golongan mutakhir yang menambahkan apa yang dikatakan oleh Salaf dan kemestian mereka memahamkan sifat-sifat Allah berdasarkan zahirnya menyebabkan mereka terjebak dalam melakukan penyamaan yang bercanggah dengan apa yang diiktikadkan oleh Salaf. Oleh itu, al-Qaradawi (2005: 47) juga mengemukakan bidasan terhadap metodologi tafsiran yang dikemukakan oleh aliran Salafiyyah Kontemporari kerana kecenderungan mereka yang meminggirkan akal menyebabkan mereka mentafsirkan ayat-ayat al-Quran dan hadith secara literal tanpa menerima sebarang pentafsiran yang lain. Sementara al-Anjari \& al-Masri (2013: 33) menegaskan bahawa ta'wil dan Tafwid telah berlaku di kalangan ulama Salaf al-Salih dan tiada berlaku di kalangan mereka yang mudah menuduh sesat atau bid'ah antara satu dengan lainnya. Andi Aderus (2012: 17) pula menjelaskan bahawa pegangan mereka yang tekstual itu menjadikan mereka mengeluarkan kelompok lain daripada Salafiyyah.

Dirumuskan bahawa kebanyakan para ulama memberikan penilaian bahawa metodologi tafsiran aliran Salafiyyah Kontemporari yang hanya secara literal ke atas keseluruhan ayat-ayat tidak dapat diterima secara mutlak. Hal ini disebabkan terdapatnya pembahagian Ayat Sifat kepada Wadih Jalli dan Khafi Mutashabih atau Mutashabih al-Sifat. Justeru pada waktu-waktu tertentu, sebahagian daripada Ayat Sifat memerlukan pentakwilan agar ia dapat difahami oleh batas pemikiran manusia dan pada waktu yang sama mereka mentanzihkan Allah daripada sifatsifat kekurangan atau penyerupaan. Selain itu, penisbahan aliran Salafiyyah Kontemporari bagi metodologi tafsiran mereka kepada Ahl al-Salaf tidak dapat diterima bulat oleh para ulama 
disebabkan terdapat hujah dan bukti-bukti kukuh yang menunjukkan penerimaan Ahl al-Salaf terhadap metode 'ta'wil' dengan syarat-syarat yang perlu dipatuhi. Perkara ini menunjukkan kepada kepelbagaian pendekatan yang digunakan oleh Ahl al-Salaf dalam tafsiran mereka termasuklah ayat-ayat Sifat.

Kepelbagaian tafsiran yang dilakukan oleh para ulama dan mufassirin itu mampu menyerlahkan peranan asas tafsir al-Quran, sebagaimana yang dinyatakan oleh Ash Shabuni (2007: 92), iaitu untuk membebaskan manusia daripada penyembahan kepada selain Jalla wa 'Ala dan mempertemukan mereka dengan Pencipta Yang Maha Agung. Pendekatan Ahl al-Salaf dalam mentafsirkan ayat-ayat Sifat dengan mengutamakan nas-nas shar'iyyah dan tanpa meminggirkan dalil-dalil 'aqli, yang bersandarkan prinsip-prinsip lughawiyyah dan balaghiyyah adalah prinsip yang menjadi pegangan Ahl al-Sunnah wa al-Jama'ah dalam mentanzihkan Allah.

Berasaskan tujuan agung itu perbezaan tafsiran di antara satu aliran dengan aliran yang lain bukanlah menjadi sebab berlakunya percanggahan fahaman (ikhtilaf tudad) dan jurang pemisah yang mengasingkan satu aliran dengan aliran-aliran yang lain. Jika percanggahan yang sedemikian itu berlaku, maka ia menyalahi kewajaran perbezaan tafsiran yang diterima oleh Islam.

\section{References}

Al-Quran al-Karim.

'Abd al-Ghani, 'Abd al-Maqsud. 1406H. Usul al-'Aqidah al-Islamiyyah. Cairo: Maktabah al-Zahra.

'Abd al-Mun'im, Mahmud 'Abd al-Rahman. N.d. Mu'jam al-Mustalahat wa al-Alfazh al-Fiqhiyyah. Vol. 2. Cairo: Dar al-Fadilah.

Aboebakar Atjeh, H. n.d. Perbandingan Mazhab Ahlus Sunnah Wal Jama'ah. n.p.: n.p.

Abu Zahrah, Muhammad. n.d. Tarikh al-Madhahib al-Islamiyyah fi al-Siyasah wa al-'Aqa'id wa Tarikh al-Madhahib al-Fiqhiyyah. Cairo: Dar al-Fikr al-'Arabi.

Andi Aderus, H. 2012. Perdebatan Seputar Salaf, Salafi dan Salafiyyah. Working Paper. Organised by Fakulti Usuluddin, Kolej Universiti Peruruan Ugama Seri Begawan. Bandar Seri Begawan. 20 March 2012.

a-Anjari, Fouzi dan Al-Masri, Hamdi Sinan. 2013. Al-Asha'irah: Akidah Sebenar Ahli Sunnah Wal Jamaah. Trans. By al-Ghari, Zamihan Mat Zin \& Hj. Dan Mohd Shairodhi Mat Ali. Selangor: AlHimna Enterprise.

al-Ashqar, 'Umar Sulayman 'Abdullah. 1424H/2004M. Asma' Allah wa Sifatuhu fi Mu'taqidi Ahl alSunnah wa al-Jama'ah. Jordan: Dar al-Nafa'is.

Ash Shabuni, Muhammad Ali. 2007. Ummu al-Quran Sejarah dan Dasar Pengajian Ilmu al-Quran. Trans. \& ed. by al-Hashimi, M. Junaid. Abdul Aziz Ismail. Kuala Lumpur: al-Hidayah Publications.

al-Bayjuri, Ibrahim bin Muhammad bin Ahmad. 1424H/2004M. Tuhfah al-Murid Sharh Jawharah al-Tawhid. Al-Khalili, Abdullah Muhammad (ed.). Beirut: Dar al-Kutb al-'Ilmiyyah.

al-Buti, Muhammad Sa'id Ramadan. 1990. Al-Salafiyyah Marhalah Zamaniyyah Mubarakah La Madhhab Islami. Damascus: Dar al-Fikr.

Farghal, Yahya Hashim Hasan. 2000. Al-Firaq al-Islamiyyah fi al-Mizan. Al-'Ain: United Arab Emirates University.

Hasan, 'Izzah Mohammed. 1414H/1993M. Qanun al-Ta'wil Baina al-Mu'tazilah wa al-Isha'irah wa Ibn Rusd. n.p.: n.p.

Al-Hilaly, Salim bin I'd. 1422H/2001M. Manhaj Salaf Manhaj Alternatif. Trans. by Andi Arlin \& ed. by Abu Rania. Jakarta: Pustaka Azzam.

Hilmi, Mustafa. 2005. Manhaj 'Ulama' al-Hadith wa al-Sunnah fi Usul al-Din. Beirut: Dar al-Kutb al-'Imiyyah.

Ibn Taymiyyah, Ahmad. 1381H. Majmu' Fatawa. Al-'Asimi, 'Abd al-Rahman bin Muhammad bin Qasim \& Muhammad bin 'Abd al-Rahman (eds.). Vol. 3. n.p.: Matabi' al-Riyad. 
al-Juhari, Abu Nasr Isma'il bin Hammad. 1430H/2009M. Al-Sahhah Taj al-Lughah wa Sahhah al'Arabiyyah. Tamir, Muhammad Muhammad, al-Sami, Anas Muhammad \& Ahmad, Zakariyya Jabir (eds.). Cairo: Dar al-Hadith.

al-Jurjani, 'Ali bin Muhammad. 1403H/1983M. Kitab al-Ta'rifat. Beirut: Dar al-Kutub al-'Ilmiyyah. a-Khatib, Ahmad Sa'ad. 1431H/2010M. Mafatih al-Tafsir. Vol. 1 \& 2. Riyadh: Dar al-Tadmuriyyah. Khalif Muammar A. Harris. 2012. Pseudo-salafi, ekstrimisme dan keruntuhan autoriti. Jurnal Kefahaman Ahli Sunnah Waljama'ah 2: 165-197.

al-Lajnah al-Da'imah li al-Buhuth al-'Ilmiyyah wa al-Ifta'. 1426H/2005M. Fatawa al-'Aqidah. Cairo: Dar Ibn al-Jawzī.

Mudasir Rosder dan Hamzah Harun al-Rasyid. 2012. Metod pemikiran al-Ash'ari dan relevennya dengan pemikiran Salaf. Jurnal Kefahaman Ahli Sunnah Waljama'ah 2: 1-23.

Muhammad Rashidi Wahab \& Syed Hadzrullathfi Syed Omar. 2012. Takwilan nas-nas sifat Mutashabihat dalam kalangan Salaf. Global Journal al-Thaqafah 2 (2): 77-85.

al-Qaradawi, Yusuf. 1426H/2005M. Fusul fi al-'Aqidah bayn al-Salaf wa al-Khalaf. Cairo: Maktab Wahbah.

al-Razi, Muhammad bin Abi Bakr bin 'Abd al-Qadir. N.d. Mukhtar al-Sahhah. n.p. Dar al-Manar.

Sarinah Yahya. 2015. Manhaj tafsiran Ayat Sifat dalam mushaf Brunei Darussalam dan terjemahannya. pp. 210-221.

al-Saqqaf, Hasan 'Ali. 2007. Al-Salafiyyah al-Wahabiyyah Afkaruha al-Asasiyyah wa Judhuruha alTarikhiyyah. Beirut: Dar al-Imam al-Rawwas.

Shahrastani. 2006. Al-Milal wa al-Nihal Agama dan Ideologi. Trans. Muhammad Ramzi Omar. Kuala Lumpur: Dewan Bahasa dan Pustaka.

al-Sharif, Mahmud. 1404H/1984M. Al-Tabari wa Manhajuhu fi al-Tafsīr. Saudi Arabia: Maktabah 'Ukaz

al-Suyuti, Abu al-Fadl Jalal al-Din 'Abd al-Rahman Abi Bakr. 1411H/1991M. Al-Itqan fi 'Ulum alQuran. Vol. 2. Beirut: Dar al-Kutb al-'Ilmiyyah.

al-Tabari, Abu Ja'far Muhammad bin Jarir. 1412H: 1992M. Tafsir al-Tabari al-Musamma Jami' alBayan fi Ta'wil al-Quran. Vols. 1 \& 4. Beirut: Dar al-Kutb al-'Ilmiyyah.

Tafsir Pimpinan al-Rahman kepada Pengertian al-Quran (30 Vols.). 1416H/1995M. Trans. By Abdullah Basmeih, Syeikh. Kuala Lumpur: Bahagian Hal Ehwal Islam, Jabatan Perdana Menteri.

al-'Uthaymin, Muhammad Salih. 1424H/2003M. Tafsir al-Quran al-Karim Surah Yaa Siin. Riyadh: Dar al-Thurayya li al-Nashr.

al-'Uthaymin, Muhammad bin Salih. n.d. Fath Rabb al-Bariyyah bi talkhis al-Hamawiyyah. n.p.: n.p. http://d1.islamhouse.com/data/ar/ih-books/single3/ar_Explanaition_of_aSummary_of_ alAqeedat_ulHamawiyyah_pdf Retrieved: 8 October 2015.

al-Utsaimin, Muhammad Shalih (ed.). 2014. Syarah Pengantar Studi Ilmu Tafsir Ibnu Taimiyah. Trans. S. Th. I, Solihin. Jakarta: Pustaka al-Kautsar.

al-Zarkashi, Badr al-Din Muhammad bin 'Abdullah. 1988. Al-Burhan fi 'Ulum al-Quran. Ibrahim, Muhammad Abu al-Fadl (ed.). Vol. 2. Beirut: Dar al-Jayl.

al-Zarqani, Muhammad 'Abd al-'Azhīm. 1409H/1988M. Manahil al-'Irfan fi 'Ulum al-Quran. Vol. 2. Beirut: Dar al-Kutub al-'Ilmiyyah.

al-Zuhayli, Wahbah. 1988. Usul al-Fiqh al-Islami. Vol. 1. Damascus: Dar al-Fikr. 